\section{Reforming the Mental Health Act}

\author{
ADRIAN GROUNDS
}

The Government's White Paper, ${ }^{1}$ Reforming the Mental Health Act (Department of Health, 2000), was published in December 2000. Part I describes the proposed new legal framework and Part II summarises proposals for high-risk patients. $^{2}$ The White Paper is a profoundly illiberal document.

\section{BACKGROUND}

We are set to embark on the third era of mental health law reform in half a century. In each case, in the 1950s, the 1970s and the late 1990s, those charged with the task of reviewing the law have recognised that legislation has to balance the rights of individual patients and the public, but the primary policy concerns driving reform on each occasion have been very different. A central purpose of the Percy Commission (1957) was to assess the extent to which people with mental disorders could be treated as voluntary patients. In summary, it concluded:

\begin{abstract}
". . . that the law should be altered so that whenever possible suitable care may be provided for mentally disordered patients with no more restriction of liberty or legal formality than is applied to people who need care because of other types of illness, disability or social difficulty" (Percy Commission, 1957, para. 7).
\end{abstract}

The subsequent 1959 Mental Health Act was heralded as a great piece of liberalising legislation, but its reputation became tarnished by concern about failures of services and abuses of professional power. The Act was seen as being deficient in safeguarding the rights of detained patients,

I. British governments consult widely on some policy matters before drafting a bill for Parliament to consider. An early consultation document is called a Green Paper and a final statement of intent prior to publication of a bill is called a White Paper.

2. The White Paper deals with mental health legislation in England and Wales. Scotland will deal with the matter through its own Parliament. and in introducing its subsequent review the Government noted:

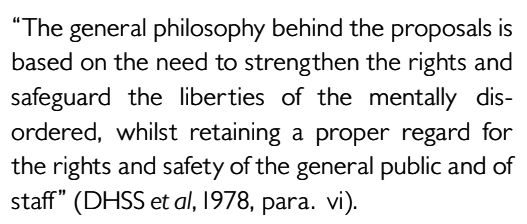

The new White Paper arises from a different context of concern. It is presented as part of a wider strategy to 'modernise' mental health services. The structure of mental health legislation needs to reflect the changing nature of mental health care: it no longer makes sense to have a set of powers predominantly for detention in hospital when the community has become the primary locus of care and the hospital estate has contracted substantially. However, at the same time there is at least scepticism (if not a wish to write the obituary) of community care, and public protection has become a primary expectation of psychiatric services in mental health policy (Department of Health, 1998). There are two other developments: the growing body of work on mental capacity (Law Commission, 1995), which is fuelled intermittently by troubling legal cases; and the consultation document Managing Dangerous People with Severe Personality Disorder (Home Office \& Department of Health, 1999) in which the public protection agenda takes centre stage.

The White Paper's early development began with the commissioned review of the Expert Committee chaired by Professor Genevra Richardson (Department of Health, 1999a). The Richardson Committee produced a generally impressive report stressing that legislation should be based on a set of balancing principles to guide its interpretation. In particular, the committee strove to emphasise non-discrimination against those with mental disorders, and a balance between compulsion and entitlement so that duties to comply with care and treatment are balanced by a parallel duty on authorities to provide appropriate standards.

Responsibility for the subsequent development of the proposals then returned to the Department of Health, where the review grew into the Department's Green Paper (Department of Health, 1999b) and its character began to change. It became harder in tone and less balanced, liberal and principled. The shift of emphasis was exemplified by the Green Paper's changes to the set of guiding principles proposed by Richardson: informal care was diluted, safety was introduced and reciprocity and entitlement were omitted. Instead of a principle of entitlement, the Government preferred instead to rely on the general duties placed on health and social services authorities and its own National Service Framework standards (Department of Health, 1999c). This ignores the need to elevate care provision to the realm of rights because of the traditional weakness of our legislation in providing remedies in this area. The greater extension of compulsory civil powers into the community will highlight more starkly that social care and housing agencies often lack a sense of obligation and commitment towards 'difficult' patients. The remedy of enforceable individual rights to care is an important counterbalance: without it, we will not have enabling powers but disabling powers. Reluctance to grasp the Expert Committee's advice about this may come to be seen as a serious failure.

\section{THE NEW LEGAL FR AMEWORK}

The White Paper broadly adopts the framework of the Green Paper but goes even further in the direction of compulsion at the expense of safeguards. It is instructive to read the Richardson review, the Green Paper and the White Paper side by side and to trace the sequence of shifts, omissions and additions, the subtle changes of wording and the proposals quietly dropped.

The White Paper proposes the adoption of a broad definition of mental disorder, a single pathway for compulsory powers, their extension to community as well as hospital settings and independent authorisation if such powers are to extend beyond 28 days. These broad aims are welcome, but the proposals themselves raise concerns. Detail often is lacking in the text and it is a long way from draft legislation. 
The White Paper takes the definition of mental disorder suggested by the Richardson Committee, namely:

". . . any disability or disorder of mind or brain, whether permanent or temporary, which results in an impairment or disturbance of mental functioning" (Department of Health, 2000, Part I, para. 3.3)

The recommendation, which appears to be accepted in the Green Paper, that this should exclude cases where diagnosis solely relates to disorders of sexual preference, or misuse of alcohol or drugs, does not appear in the White Paper. Does this imply that the new legislation will extend to these groups?

The question is important because the White Paper already proposes a wide and open gateway to initiating compulsory powers, and adding the above groups will make it wider still. The first stage of the pathway to compulsory powers will be a prompt, preliminary assessment carried out by two doctors and a social worker or other suitably trained mental health professional. Insistence that referrals are filtered through general practitioners (GPs) will no longer be an option. Trusts providing specialist mental health services will be under a statutory obligation to arrange a preliminary examination of whether a person meets the criteria for compulsory powers, following a reasonable request from a patient, a patient's carer, GP, the police, probation service or prison service. This will include requests concerning people with personality disorders and sexual and violent offenders in the community. The potential demand could be considerable.

The second stage of procedures for compulsory powers will consist of a full assessment of the patient's care needs and initial treatment, and has a maximum period of 28 days. No treatment other than urgent treatment can be given without consent before a preliminary written care plan is completed, and this should be done within 3 days. Compulsory care beyond 28 days would be a third stage and would require a care and treatment order independently authorised by the new Mental Health Tribunal on the recommendation of the patient's clinical supervisor. Lead responsibility in exercising compulsory powers will no longer rest with a responsible medical officer: the clinical supervisor could be a consultant psychiatrist or consultant psychologist.

The initial criteria for a care and treatment order are similar to those that currently apply, namely, that the person has a mental disorder and it is of a nature or degree warranting specialist care and treatment. However, the White Paper then makes a distinction between the patient's interests and those of others. If the compulsory powers are needed in the patient's best interests, there must be a care plan that is expected to be of therapeutic benefit. If the powers are needed because of risk to others, there must be a plan that prioritises risk management for treating the underlying disorder or managing behaviours arising from it. (However, the concept of therapeutic benefit is so broadly defined that it hardly amounts to a higher standard.)

\section{OFFENDERS WITH MENTAL DISORDERS}

In relation to offenders with mental disorders, the current drafting of the White Paper appears to indicate significant extensions of sentencing powers that were not canvassed in the Green Paper. First, the 'hybrid order' (hospital and limitation direction) will apply to any mental disorder (raising the spectre of mentally ill offenders being subject to long prison terms). Second, although there is no stated intention to broaden the criterion for restriction orders imposing indeterminate detention, the White Paper states that they could be made where the clinical assessment indicates that the offender poses a significant risk of serious harm to others, or because of the nature of the current offence or previous convictions. This departs from the present sole criterion (expounded in R. $v$. Birch, 1989) that the order is necessary to protect the public from serious harm.

\section{HIGH-RISK PATIENTS}

Part II of the White Paper develops some of the proposals outlined in Managing Dangerous People with Severe Personality Disorder (DSPD) (Home Office \& Department of Health, 1999). The above framework of civil powers will apply to this group. Criminal justice agencies and others will be able to refer high-risk individuals for preliminary assessment. Up to 28 days' detention in a National Health Service (NHS) secure unit specialising in DSPD assessment could follow, with further detention and treatment thereafter. Courts will be able to order that defendants are transferred for specialist DSPD assessment before sentencing, and the Home Secretary could direct the transfer of a prisoner for specialist assessment in a hospital or a dedicated prison unit. (The latter option may have to meet the standards upheld in the case of Aerts $v$. Belgium, 1998.) The last part of the White Paper reviews progress to date in the development of specialised DSPD services. Over 100 additional secure NHS places and 180 prison places for the DSPD group are envisaged over the next few years. However, on an inconsistent note, the White Paper reveals uncertainty over the future of the largest NHS specialist service for offenders with personality disorder (approximately 100) at Ashworth Hospital, now improved after past inquiries. The expertise there will be needed if the net expansion indicated in the White Paper is to be met.

\section{SAFEGUARDS}

The White Paper broadens the legal concept of mental disorder, widens the net of compulsion into the community, seeks to draw more offenders with personality disorder into the ambit of mental health legislation and expands sentencing powers. Such developments require strong counterbalancing safeguards. But the safeguards in the White Paper are significantly weaker than those of our current Mental Health Act, despite its claims to the contrary.

The fundamental change in the role of the tribunal is most important. The mental health review tribunal was established as a safeguard for patients against improper admission and unduly protracted detention. It enabled independent review of the decisions of those authorising detention, and its strength as a safeguard derived from the separation of those functions. Under the proposals of the White Paper the new tribunal will become both a body for authorising detention and one to which patients apply for ending compulsion. Properly independent reviews of compulsion are ruled out.

The White Paper omits safeguards outlined in the Green Paper, namely the criterion that compulsory care and treatment should be in the least restrictive appropriate setting, and the choice by a patient of a 'nominated person' to represent them. (In the White Paper the choice is made by the social worker involved in the application for compulsory powers.) The role of the new Commission for Mental Health will be weaker than that of the current Mental Health Act Commission in several respects: 
it will lose the responsibilities for visiting (which will fall to the Commission for Health Improvement or the National Care Standards Commission) and for proposing changes to the Code of Practice. Patients will have access to an advocacy service but advocates may not have the rights (e.g. of access) recommended by the Richardson Committee. The complex divisions of role among these bodies may not serve patients well.

The White Paper contains much more than is indicated here. Representations about its deficiencies must be robust. We should also recall the conclusions of Paul Appelbaum's fine book, Almost a Revolution (1984), in which he reviewed the outcome of the waves of mental health law reform that have taken place in the USA. In brief, he found that changes in the law had less impact than anticipated on the practice of mental health services. The advocates of reform did not have their hopes fulfilled, and the critics who prophesied dire consequences also turned out to be wrong. Psychiatric services changed less than expected. It is a conclusion that is both reassuring and depressing.

ADRIAN GROUNDS, FRCPsych, Institute of Criminology and Department of Psychiatry, University of Cambridge, 7 West Road, Cambridge CB3 9DT, UK. E-mail: agII3@cam.ac.uk

(First received I February 200I, final revision I8 June 200I, accepted I8 June 200I)

\section{DECLARATION OF INTEREST}

None.

\section{REFERENCES}

Appelbaum, P. S. (1984) Almost a Revolution: Mental Health Law and the Limits of Change. Oxford: Oxford University Press.

Department of Health (1998) Modernising Mental Health Services: Safe, Sound and Supportive. London: Department of Health.

- (1999a) Report of the Expert Committee: Review of the Mental Health Act 1983. London: Department of Health.

_ (1999b) Reform of the Mental Health Act 1983 Proposals for Consultation (Cmnd 4480). London: $\mathrm{HMSO}$

- (1999c) The National Service Framework for Mental Health. London: Department of Health.
- (2000) Reforming the Mental Health Act (Cmnd 5016-I-II). London: HMSO.

DHSS, Home Office, Welsh Office, et al (1978) Review of the Mental Health Act 1959 (Cmnd 7230). London: HMSO.

Home Office \& Department of Health (1999) Managing Dangerous People with Severe Personality Disorder: Proposals for Consultation. London: Home Office.

Law Commission (1995) Mental Incapacity (Cmnd 23I). London: HMSO.

Percy Commission (1957) Report of the Royal Commission on the Law Relating to Mental Illness and Mental Deficiency 1954-1957 (Cmnd 169). London: $\mathrm{HMSO}$

Aerts v. Belgium (1998) EHRR 777.

R. v. Birch (1989) 90 CrAppR 78, CA. 